\title{
Stained prawn disease (SPD) of Pandalus platyceros in British Columbia, Canada, caused by a rickettsial infection
}

\author{
Susan M. Bower *, Gary R. Meyer, Jim A. Boutillier \\ Department of Fisheries and Oceans, Biological Sciences Branch, Pacific Biological Station, Nanaimo, British Columbia, \\ Canada V9R $5 \mathrm{~K} 6$
}

\begin{abstract}
Stained prawn disease (SPD) with clinical signs of black discolouration of the cuticula, especially around the edges of body segments, and black stippling on the surface of the hepatopancreas was caused by a rickettsia-like microorganism with an affinity for fixed phagocytes and haemocytes. This disease was found in prawns from various localities throughout Howe Sound and at one location in the Strait of Georgia, British Columbra, Canada. The distribution of SPD within Howe Sound has not changed since it was first detected in 1989. However, the prevalence has declined to about $4 \%$ from a record high of about $15 \%$ in July 1990 and March 1991 In areas with these high prevalences, an above-average level of mortality, equated to a decline in survival rates from 57 to $15 \%$, was detected. These mortalities were not attributable to fishing pressure because the affected area has been closed to fishing since November 1988 due to unacceptable levels of dioxin and furan compounds In shellfish tissue samples. Laboratory studies indicated that the SPD agent can be transmitted horizontally by cannibalism and via the water [exposure to screened ( $1 \mathrm{~mm}$ pore size) effluent from infected prawns] and remained infectious for $10 \mathrm{~d}$ or more of storage at $-10^{\circ} \mathrm{C}$. About $50 \%$ of the prawns that fed on infected prawns (both fresh and after being frozen) and $25 \%$ of the prawns exposed to contaminated water became infected. Most mortalities attributable to SPD occurred between 2 and 4 mo after exposure to the etiological agent in the laboratory
\end{abstract}

KEY WORDS: Pandalus platyceros - Rickettsia-like microorganism - Stained prawn disease (SPD)

\section{INTRODUCTION}

The spot prawn Pandalus platyceros supports a valuable trap fishery in British Columbia, Canada, that began in the early 1900s in the southern Strait of Georgia and has gradually expanded to include the entire coast of British Columbia. Since the late 1970s, extensive sampling has been undertaken by biologists in the Canadian Department of Fisheries and Oceans for stock assessments. However, it was not until recently that a new disease was encountered in spot prawns from Howe Sound. In fall 1989, a dark stainlike discolouration was observed on the cuticula of a few prawns $(<1 \%)$ from the Woolridge Island area (Thornbrough Channel) of Howe Sound (Location 18

·E-mail: bowers@pbs.dfo.ca in Fig. 1). Superficially, affected prawns appeared as though they had been dipped in a dark staining material that tended to accumulate along the edges of the body segments, resulting in the name stained prawn disease (SPD). From late 1988 to date (early 1995), about half of Howe Sound, including Thornbrough Channel, has been closed to fishing due to contamination with dioxin and furan compounds, while the remaining area remained open to commercial prawn fishing (Fig. 1). As a result, the rebuilding of prawn populations in the closed areas, including those affected by SPD, could be monitored using research cruises. Investigations were initiated to determine the cause of SPD, its distribution and prevalence in the field, and what if any effects it would have on the productivity of prawn populations. In addition, laboratory experiments were conducted to determine the infectivity and pathogenicity of the etiological agent. 


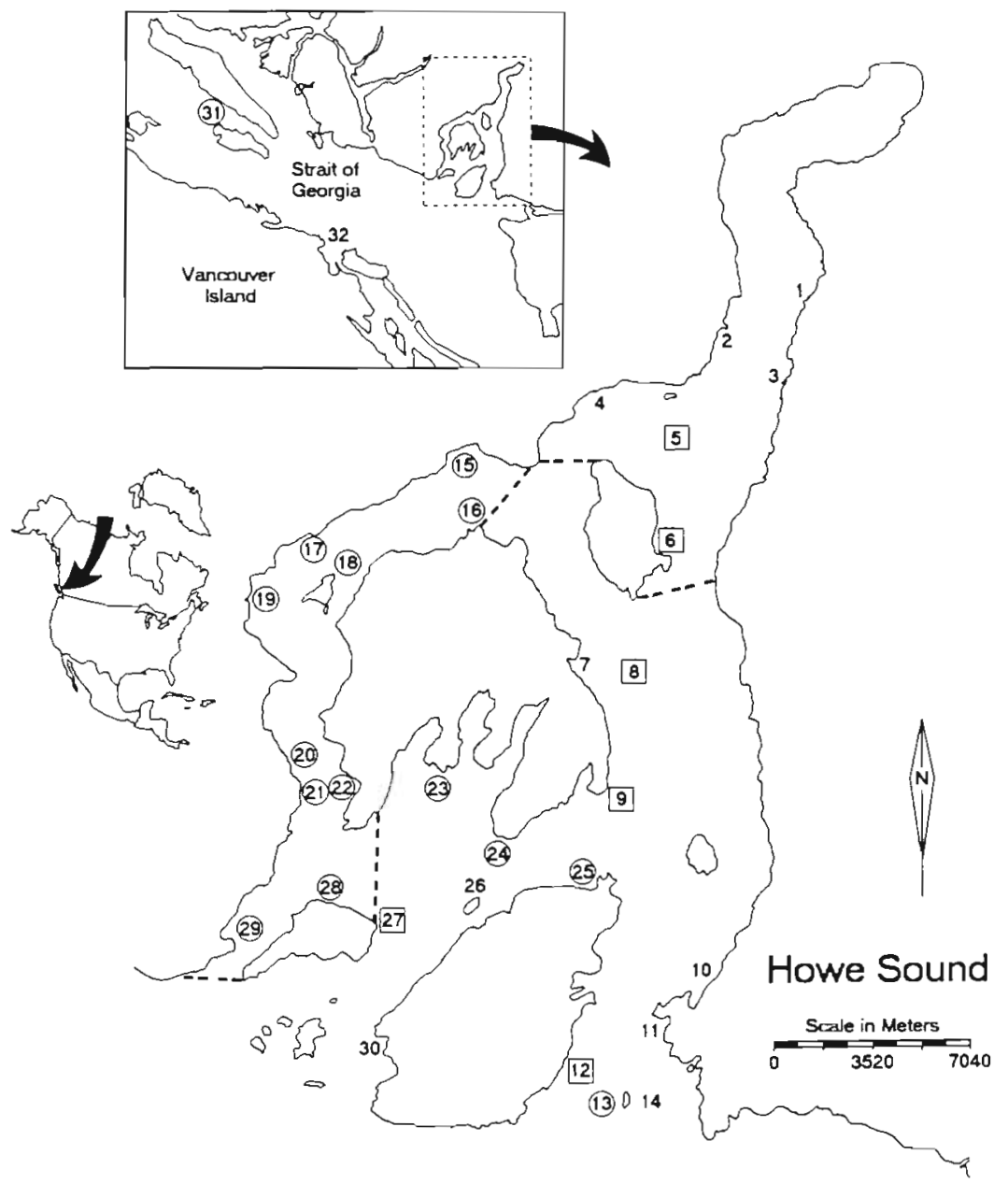

Fig. 1. Numbers indicate localities in British Columbia, Canada, from which Pandalus platyceros were examined for stained prawn disease $(\mathrm{SPD}$, caused by a rickettsialike microorganism) between 1 March 1990 and 29 October 1993 (see Table 1 for details). Circles indicate places where the occurrence of SPD has been confirmed by histological examination. Squares indicate areas from which visible signs of infection have been reported but the presence of SPD has not yet been confirmed by histological examination. Unmarked numbers indicate locations in which prawns were examined histologically for SPD but the disease was not found nor have visible signs of infection been reported from these locations. All areas in Howe Sound west and north of the dashed lines were closed to commercial prawn fishing in November 1988 and remained closed for the duration of this study

\section{MATERIAL AND METHODS}

Identification of pathogen. All tissues were fixed in Davidson's solution with acetic acid (Shaw \& Battle 1957). Initially, affected prawns were fixed intact. However, to improve the fixation of internal organs, prawns were dissected prior to fixation by removing and discarding the abdomen and the appendages of the cephalothorax, and slitting open the carapace middorsally without disrupting the underlying organs. It was later recognized that SPD could be identified by examining only the hepatopancreas, which was removed from each prawn prior to fixation.

For microscopic examination (100 to $1000 \times$ magnification), fixed tissues were prepared using routine histological techniques. Deparaffinized sections $(5 \mu \mathrm{m}$ thick) were stained with Harris's modified haematoxylin and $0.5 \%$ alcoholic eosin as described by Lillie (1965, p. 176-177), Gram's stain, and Macchiavello's stain for rickettsiae (Clark 1981) modified by using a counterstain of $0.1 \%$ methylene blue in distilled water without phenol.
For ultrastructure examination, small pieces from the surface of the hepatopancreas of a prawn, $84 \mathrm{~d}$ after exposure in the laboratory, were fixed in $4 \%$ glutaraldehyde in Millonig's phosphate buffer (0.1 M, pH 7.4). The tissue was postfixed in $1 \%$ osmium tetroxide in the same buffer, dehydrated in ethanol, and embedded in Epon. Sections were stained with uranyl acetate followed by lead citrate before being examined with a Philips electron microscope 300.

Field surveys. Prawns from 30 locations in Howe Sound and 2 locations in the Strait of Georgia were sampled from one to several times between March 1990 and October 1993 (Fig. 1, Table 1). Prawns were captured in traps that were baited, set at $18 \mathrm{~m}$ intervals on a longline, and soaked overnight. At each location, the number of prawns per trap was noted and 5 to $100 \%$ of all prawns caught in the set were examined for SPD depending on the number caught and time available for processing.

The surveys for SPD were part of a larger study to monitor prawn stocks in Howe Sound as described by Boutillier (1993). Data from this study were used to 
Table 1. Prevalence of stained prawn disease (SPD) in Pandalus platyceros from 32 locations in British Columbia, Canada, between 1 March 1990 and 29 October 1993. Location numbers refer to Fig. 1. Depth: depth of set (m); N: no. examined for SPD; $\%$ : percentage of the total catch examined. Prev.: Prevalence of infection. ?: not known. "Locations at which the presence of SPD was not confirmed by histological examination, but visible signs of the disease were reported in a 'few' prawns on other dates

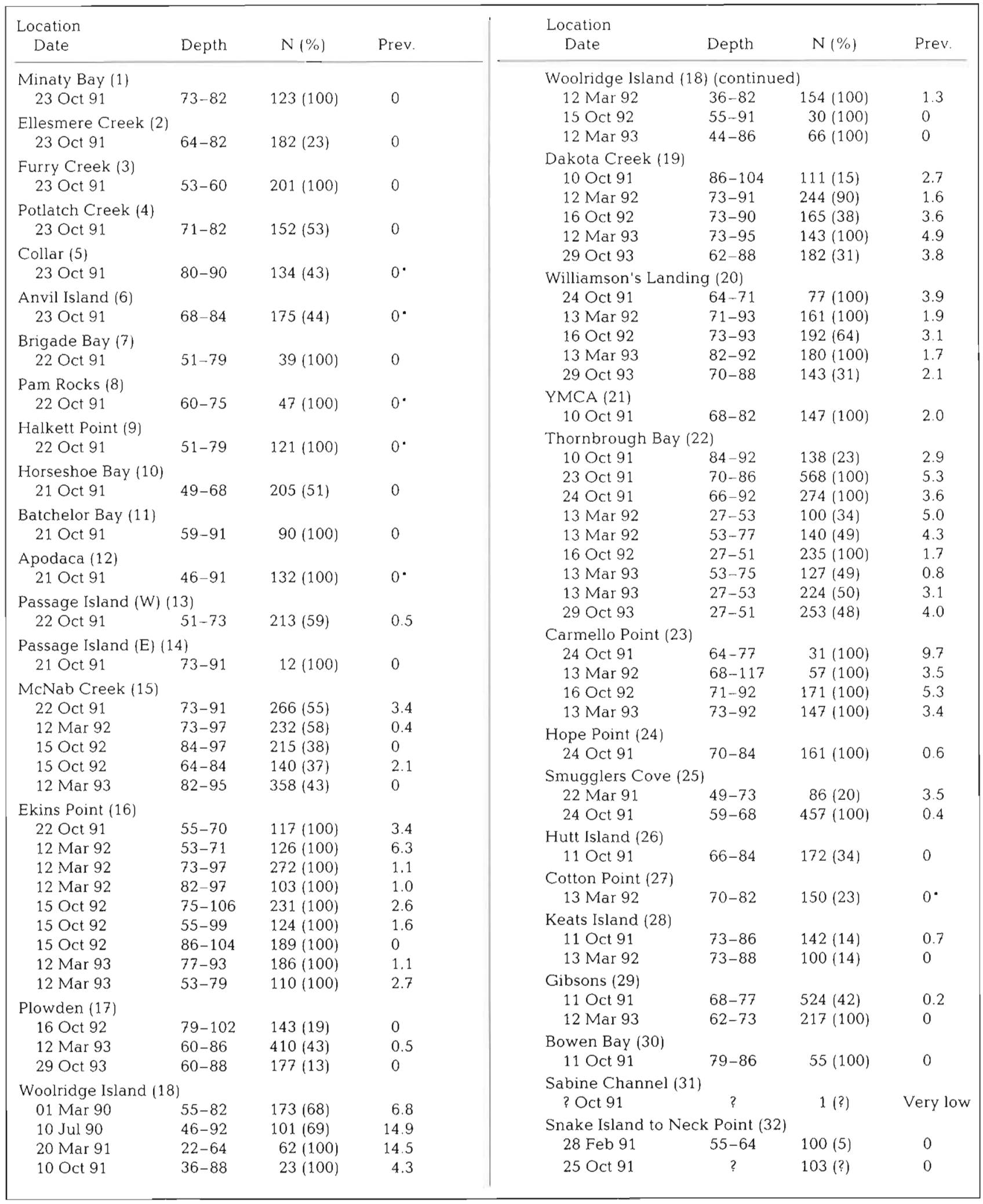


ascertain the relative effect of SPD on prawn populations. In the areas of Howe Sound closed to fishing, estimates of total mortality rates $(Z)$ were calculated for the combined age classes that are fully recruited to the fishing method (i.e. $2+$ and $3+$ yr old prawns) using the formula of Gulland (1983):

$$
Z=-\left[1 /\left(t_{2}-t_{1}\right)\right] \ln \left(n_{2} / n_{1}\right)
$$

where $t_{1}$ and $t_{2}$ are 2 points in time (expressed as proportions of a year) within the shrimp year (April to March), and $n_{1}$ and $n_{2}$ are relative estimates of abundance (standardized catch per unit effort as described by Boutillier 1988) of the combined $2+$ and $3+$ prawns in the sampling locations at these 2 points in time. In a fished population, the total mortality rate would equal the natural mortality rate $(M)$ plus the fishing mortality rate. In the closed areas with no fishing mortality, $Z=M$. The survival rate is $S=e^{-Z}$ (Ricker 1975).

Laboratory experiments. During the 2 sets of experiments conducted in the laboratory, from 41 to 78 prawns were held in each of 4 tanks (about 200 l with a bottom surface area of about $0.5 \mathrm{~m}^{2}$ ) supplied with flow-through sea water $\left(4 \mathrm{l} \mathrm{min}^{-1}\right.$, salinity 28 to $30 \mathrm{ppt}_{\text {, }}$ and temperature 8.3 to $11.8^{\circ} \mathrm{C}$ ). About $100 \mathrm{~g}$ of fresh or frozen chunks of tissue from herring, salmon, squid, oysters, or scallops were placed in each tank every 2 to $4 \mathrm{~d}$. Prior to feeding, moribund and dead prawns were removed; if they were not too decomposed nor cannibalized, tissues were preserved for histological examination. On termination of the experiments, all surviving prawns were examined histologically.

In the first set of experiments (15 March 1991 to 16 July 1991), 2 tanks (A and B) were used to monitor the survival and prevalence of infection in 115 normallooking prawns (55 and 60 prawns per tank, respectively) from the most heavily infected area in Howe Sound (Woolridge Island, Location 18 in Fig. 1). The other 2 tanks ( $C$ and D) were stocked with 'healthy' prawns ( 47 and 41 , respectively) from an area with no evidence of the disease (Snake Island, Location 32 in Fig. 1). The prawns in Tank $C$ were exposed to 34 infected prawns which were cut into about 4 pieces to promote cannibalism and the release of the infectious agent. Of these infected prawns, 8 (from Howe Sound about $6 \mathrm{~h}$ after capture) were added to Tank $\mathrm{C}$ on 15 March (Day 0) and 26 (from Tanks A and B) were added between 16 March and 25 June 1991 (Days 1 to 102). Prior to placing dead infected prawns into

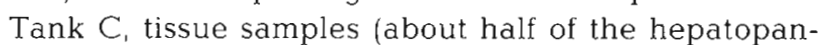
creas and a small portion of the gill and a few pereiopod coxael from each of the dead prawns were fixed for histological examination in order to verify that the prawns had SPD. Prawns in Tank D were not exposed to SPD in the laboratory and served as controls. This set of experiments was terminated on Day 123.
In the second set of experiments (25 October 1991 to 29 January 1992), 1 tank (A) held 78 prawns from the Thornbrough Bay site in Howe Sound (Location 22 in Fig. 1). Of these prawns, 18 had visible evidence of SPD at the beginning of the experiment. In addition, 3 other tanks ( $B, C$, and D) were stocked with 'healthy' prawns $(64,52$, and 58 , respectively) from Snake Island (Location 32 in Fig. 1). Prawns in Tank B were used to determine if the infectious agent could be transmitted via the water by only supplying this tank with out-flow water from Tank A that had passed through screens to eliminate matter larger than $1 \mathrm{~mm}$ in diameter. Prawns in Tank $\mathrm{C}$ were used to ascertain if the infectious agent would survive freezing (about $-10^{\circ} \mathrm{C}$ ) for at least $10 \mathrm{~d}$. On Days 3, 10, 18 and 24, five prawns (from Howe Sound with natural infections of SPD and frozen for 10 to $40 \mathrm{~d}$ ) were cut into 3 pieces and added to Tank C. After $2 \mathrm{~d}$, uncannibalized remains (usually less than $10 \%$ of the original weight) were removed from the tank. Prawns in Tank D were not intentionally exposed to SPD and served as controls. Unexpected high mortalities in Tanks A and B resulted in the termination of the experiments in these 2 tanks on Day 42. Prawns remaining in Tanks $C$ and $D$ were terminated on Day 96.

\section{RESUITS}

\section{Identification of pathogen}

Histological examination of affected prawns revealed that the dark discolouration characteristic of SPD was caused by melanized haemocytic encapsulations (up to about $200 \mu \mathrm{m}$ in diameter) below the cuticular epithelium (Fig. 2). The presence of melanin in the encapsulations was confirmed using Schmorl's reaction as described by Lightner \& Redman (1977). The melanotic encapsulations occurred in the haemal sinuses immediately below the epidermis (Fig. 2a), and in adjacent connective tissue (Fig. 2b). In heavily infected prawns, there was evidence of deterioration in the epidermis (Fig. 2c). Prawns with SPD also had melanotic encapsulations on the surface of the hepatopancreas (Fig. $3 \mathrm{~b}$ to e) and throughout the heart (Fig. 3f).

A rickettsia-like microorganism (RLM) was found to be involved in the aggregation of haemocytes that resulted in the melanotic response characteristic of SPD. Fixed phagocytes and haemocytes were the only cells infected and they contained granular micracolonies within cytoplasmic vacuoles (Fig $4 \mathrm{a}, \mathrm{c}$ ). The microcolonies (to a maximum of about $20 \mu \mathrm{m}$ in diameter) usually displaced the nucleus to the periphery of the cell (Fig. 4a). The RLM within the microcolonies stained basophilic with haematoxylin and eosin stain, 
were Gram-negative, and stained bright red to dark purple with the modified Macchiavello's stain. The modified Macchiavello's stain enhanced the visibility of RLM within melanized areas (Fig. $4 \mathrm{~b}$ ) confirming that the melanotic encapsulations were induced by the infection.

The ultrastructure of infected tissue indicated that the RLM was monomorphic, spherical in shape, and reproduced by binary fission (Fig. 4c). It possessed an indistinct cell wall with an inner plasma membrane, granular cytoplasm, and filamentous central bodies (Fig. 4d)

In the lightest infections observed, microcolonies occurred in several fixed phagocytes adjacent to haemal sinuses between the tubules of the hepatopancreas. There was no melanin associated with the infected cells and no infected cells were observed outside the hepatopancreas. In other prawns, early stages in the formation of melanotic encapsulations (Fig. 3e) were observed only in the hepatopancreas. Most of the melanotic encapsulations were at the periphery of the hepatopancreas but within the connective tissue sheath (Fig. 3b). Prawns with numerous well-formed melanotic encapsulations on the surface of the hepatopancreas also had melanotic encapsulations in the heart (Fig. 3f). Prawns with advanced infections (visible signs of SPD) had an extensive aggregation of haemocytes associated with the melanotic encapsulations on the surface of the hepatopancreas which increased the distance between the connective tissue sheath and the outer tubules of the hepatopancreas (compare Fig. 3a with Fig. 3b, c, d). They also had melanotic encapsulation in the connective tissue and haemal sinuses below the epidermis of the cuticula and in the haemal sinuses of the gills. In one heavily infected prawn, many of the haemocytes involved in the aggregations were infected, masses of RLM were free of cells, and the tips of adjacent hepatopancreatic tubules were disrupted (Fig. 3d) suggesting that the disease was in the terminal phase.

\section{Field surveys}

The numerous melanotic encapsulations were visible as black pepper-like stippling on the hepatopancreas of infected prawns from the field. This visible sign of infection occurred in all prawns with external evidence of SPD and in infected prawns that had not yet developed the cuticular discolouration. Thus, a rapid method of surveying numerous prawns from the field for SPD was developed by classifying prawns into 1 of 4 categories based on the appearance of the cuticula and hepatopancreas (Table 2). The possibility of finding infected prawns in each of the categories was assessed by the histological examination of 283 prawns (from areas where SPD occurred in the field). Because none

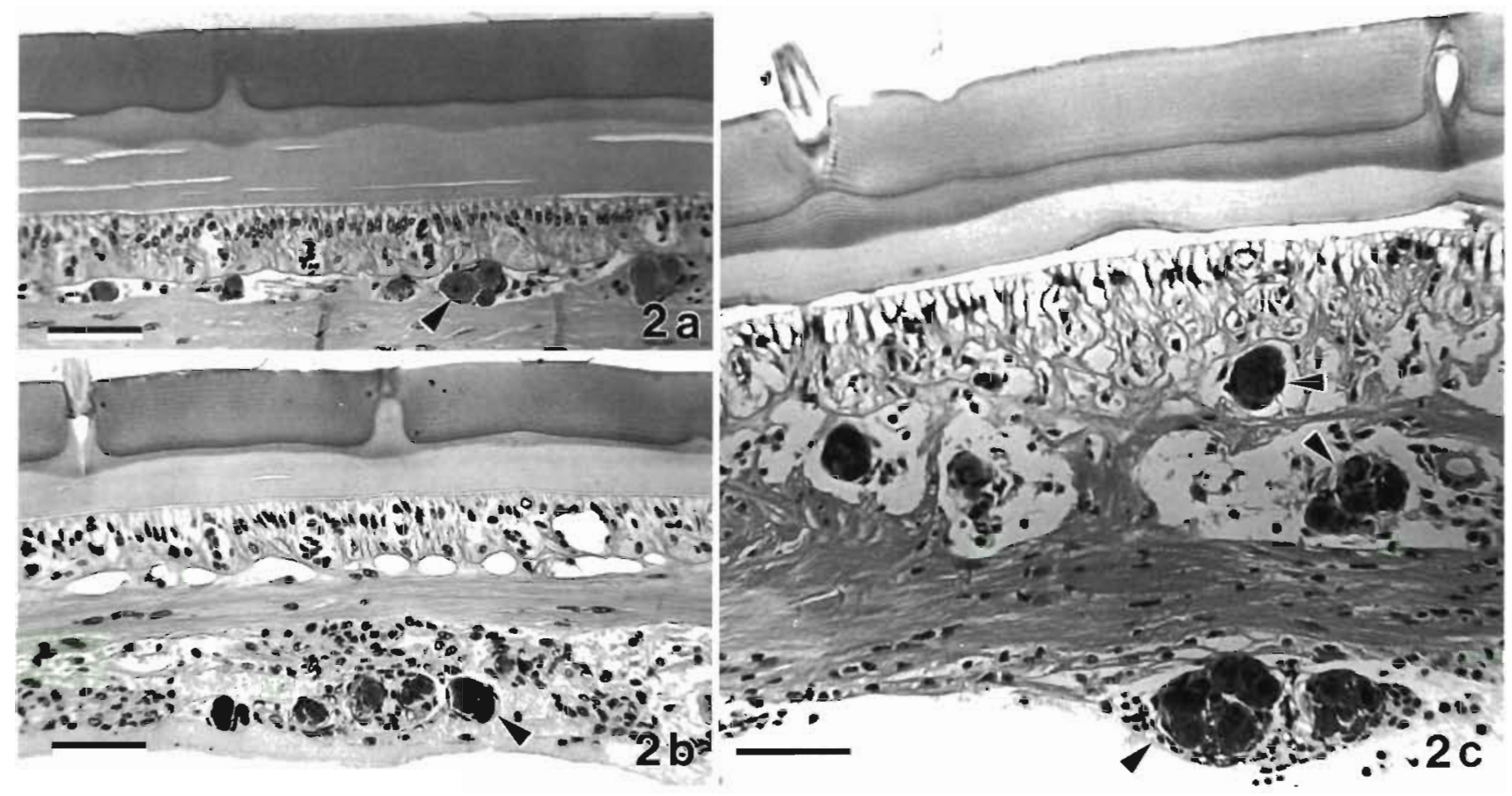

Fig. 2. Pandalus platyceros. Histological sections (haematoxylin and eosin stainj through melanized haemocytic encapsulations (arrowheads) below the cuticula that cause the discolouration characteristic of stained prawn disease. Melanotic encapsulations occurred in the haemal sinuses immediately below the epidermis (a) and in adjacent connective tissue (b). Deterioration of the epidermis in a heavily infected prawn was evident in an area adjacent to melanotic encapsulations (c). Scale bars $=100 \mu m$ 


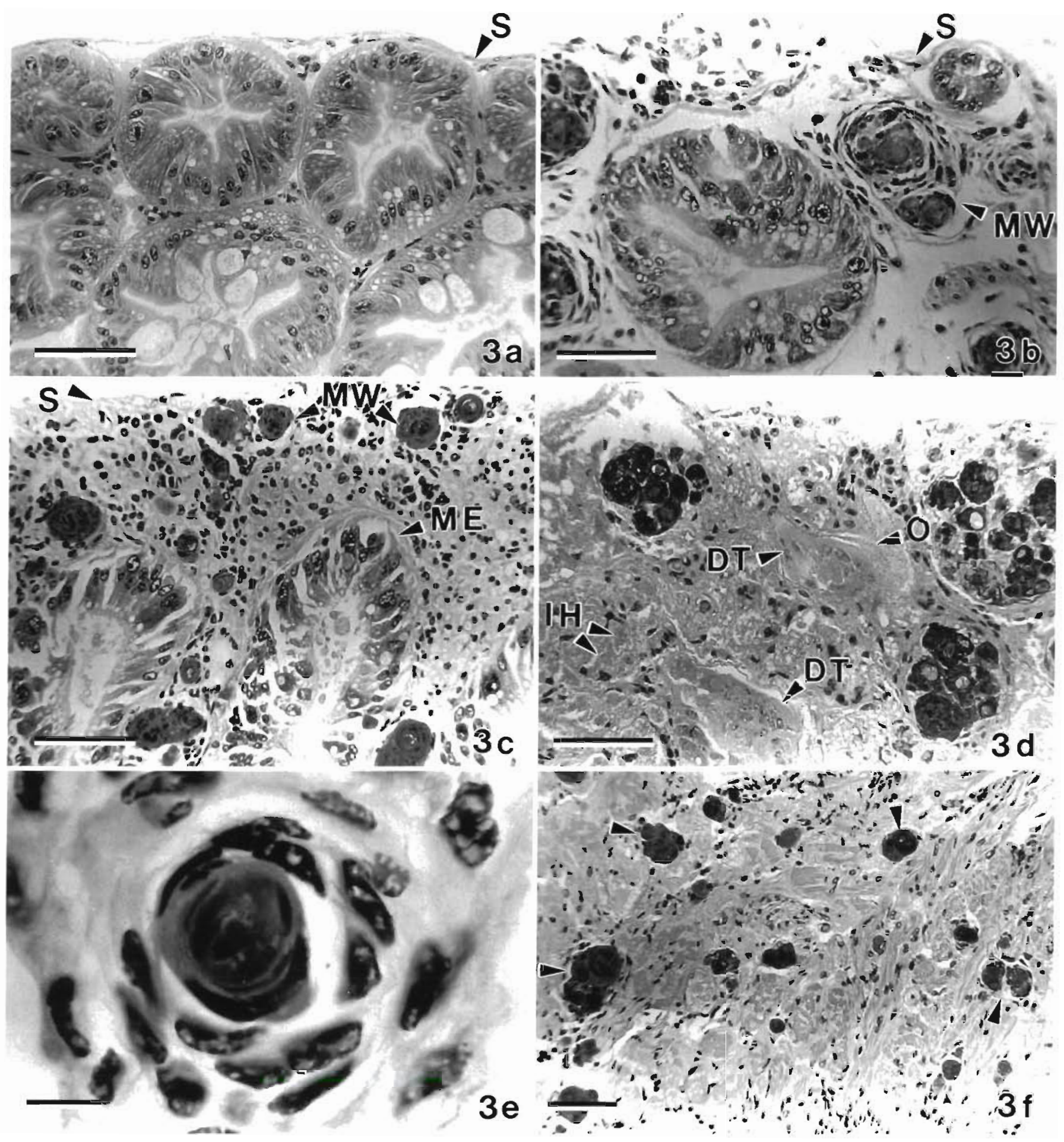

Fig. 3. Pandalus platyceros. Histological sections (haematoxylin and eosin stain) of normal prawns (a) and prawns with stained prawn disease (SPD, b to f). (a) The connective tissue sheath (S) was closely associated with outer tubules of the hepatopancreas of normal prawns. (b) Melanotic encapsulations (MW) immediately below the connective tissue sheath (S) of a prawn with a relatively light SPD infection. (c) Extensive aggregation of haemocytes and melanotic encapsulations (MW) between the connective tissue sheath (S) and the myoepithelial cells (ME) that surround the outer tubules of the hepatopancreas of a heavily infected prawn. (d) In one heavily infected prawn, many of the haemocytes involved in the aggregation were infected (IH), masses of rickettsia-like microorganism were free of cells (O), and adjacent hepatopancreatic tubules were being disrupted (DT). (e) Layers of haemocytes surround infected cells to form a typical melanotic encapsulation. (f) Melanotic encapsulations (arrowheads) also occurred in the heart of infected prawns. Scale bars $=1.00 \mu \mathrm{m}$ except for (e) where scale bar $=10 \mu \mathrm{m}$ 


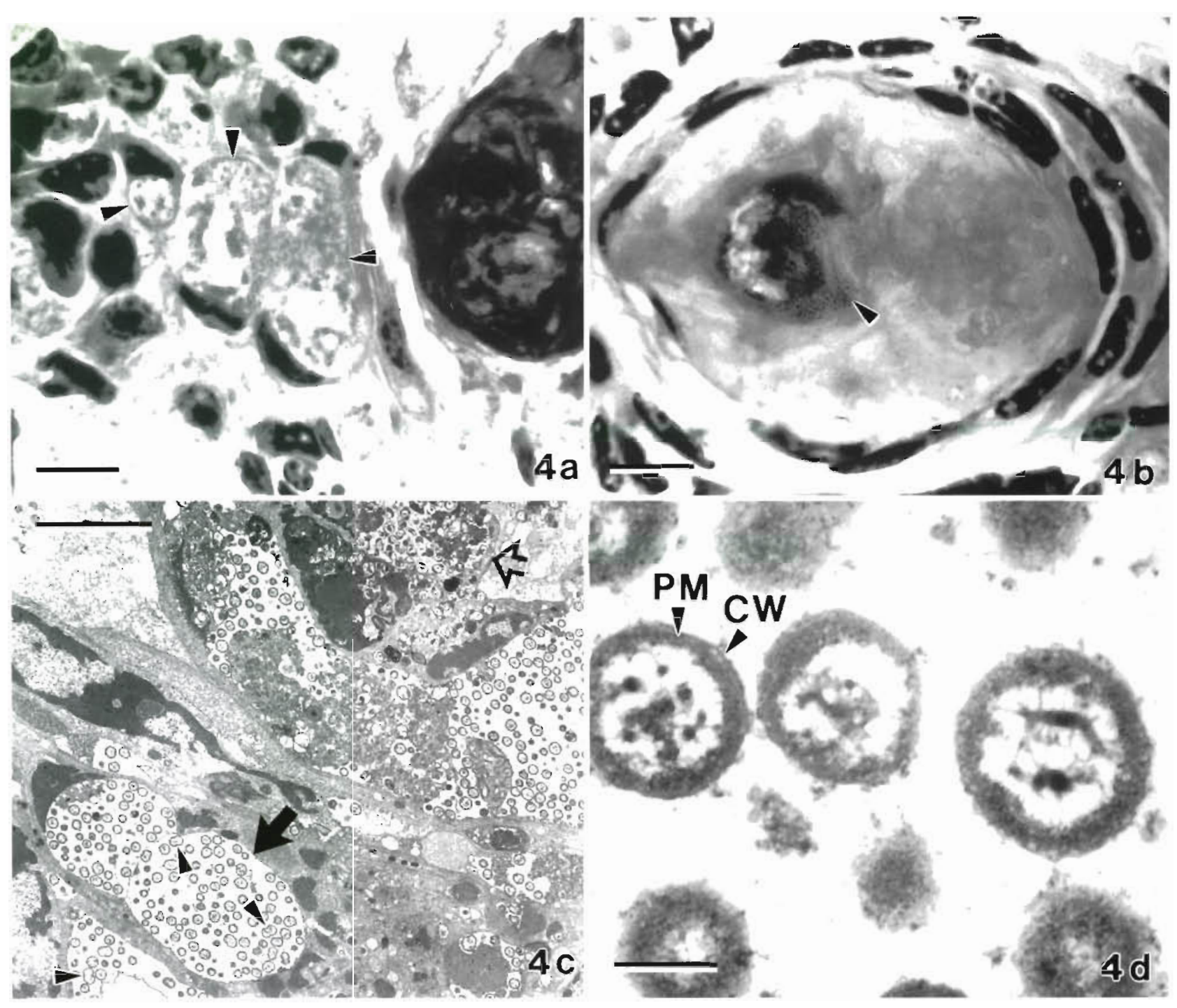

Fig. 4. Histological sections $(a, b ;$ scale bars $=10 \mu \mathrm{m})$ and electron micrographs $(c, d)$ of the rickettsia-like microorganism (RLM) that causes stained prawn disease in Pandalus platyceros. (a) Haemocytes, adjacent to a melanotic encapsulation, with large granular microcolonies (arrowheads) within cytoplasmic vacuoles that have displaced the nucleus to the periphery of the cell (haematoxylin and eosin stain). (b) RLM (arrowhead) within a melanotic encapsulation in sections stained with modified Macchiavello's stain. (c) Necrotic RLM in melanotic encapsulations (open arrow) and apparently healthy RLM, some in the process of binary fission (arrowheads), in cytoplasmic vacuole of a haemocyte (closed arrow). Scale bar $=5 \mu \mathrm{m}$. (d) Monomorphic, coccoid RLM with an indistunct cell wall (CW) surrounding an inner plasma membrane (PM), granular cytoplasm, and filamentous central bodies. Scale bar $=0.25 \mu \mathrm{m}$

of the prawns in Category 1 (normal looking cuticula and hepatopancreas) were infected with the RLM and almost all $(\geq 99 \%)$ of the prawns in Categories 3 and 4 (dark stippling on the hepatopancreas, without or with discolouration of the cuticula) were infected, visual examination was determined to be adequate for detecting if prawns in these 3 categories were infected. However, the infection was observed in about $30 \%$ of the prawns in Category 2 (normal looking cuticula with faint or questionable stippling on the hepatopancreas) Thus, histological examination of the hepatopancreas of all prawns in Category 2 was incorporated into the survey procedures for SPD. Combined survey results indicated that for every infected prawn in Category 2, there were 4 in Category 3 and 2 in Category 4.

The first survey of prawns from Howe Sound for the disease agent using histological examination techniques was conducted in March 1990 at the Woolridge Island site (Location 18 in Fig. 1). At that time, the prevalence of infection was $6.8 \%$ (Table 1). During 2 subsequent surveys in July 1990 and March 1991, the prevalence of infection was 14.9 and $14.5 \%$, respectively, the highest found to date. The prevalence of infection was about one-third as high during the next survey in October 1991 
and since October 1992, SPD has not been found at the Woolridge Island site, but the number of prawns caught at that locality has been low (Table 1).

In March 1991, SPD was confirmed at a second site (Smugglers Cove, Location 25 in Fig. 1) in Howe Sound (Table 1). Thus, in October 1991 a more extensive survey of Howe Sound, that incorporated 28 sites throughout the Sound, was conducted. Stained prawn disease was detected in prawns from most sites on the west side and mouth of Howe Sound, but SPD was not found in prawns from the east side and north end of the Sound (Fig. 1). However, unconfirmed reports of SPD occurred at 4 of the sites on the east side of Howe Sound. Except for Carmello Point where the prevalence was $9.7 \%$, the prevalence of SPD at most positive locations was $<5 \%$ and usually $<1 \%$ during the October 1991 survey (Table 1). Stained prawn disease has been detected during each survey conducted in Howe Sound since October 1991, but the prevalence of infection has not exceeded $5 \%$. Also, SPD has been found in one prawn from Sabine Channel which is outside Howe Sound but within the adjacent Strait of Georgia (Location 31 in Fig. 1, Table 1).

The natural mortality rate $(M)$ for the entire closed area of Howe Sound (Fig. 1, including the Woolridge Island site) was compared to that of the Woolridge Island site over the period of maximum prevalence (July 1990 to March 1991). There was a substantial difference in the calculated mortality rates with $M=0.56$ for the entire closed area and $M=1.905$ for the Woolridge Island site. This equates to a decline in survival rates from $57 \%$ to $15 \%$.

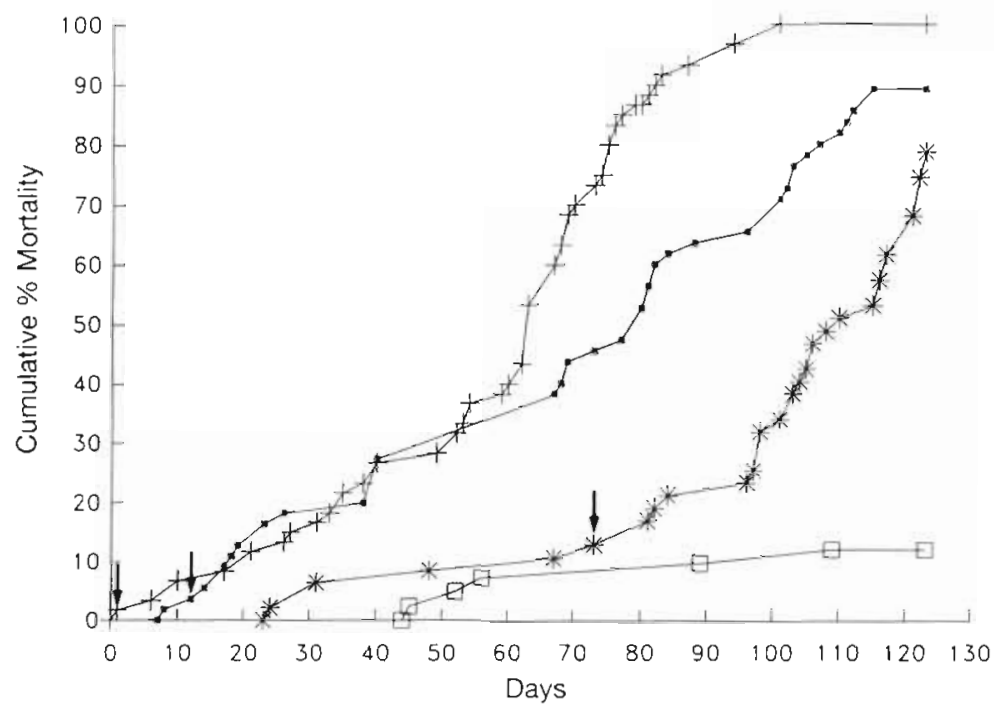

Fig. 5. Pandalus platyceros. Cumulative mortality of 203 prawns held in flow-through seawater tanks in the laboratory during the first set of experiments on the transmission of stained prawn disease (SPD). Prawns in Tank $A(\bullet, n=55)$ and Tank $B(+, \mathrm{n}=60)$ were from the Woolridge Island site in Howe Sound where the prevalence of SPD was about $15 \%$, but all prawns in both tanks appeared grossly normal at the beginning of the experiment. Prawns in Tank $C(*, n=47)$ and Tank $D(\square, n=41)$ were from the Snake Island area in the Strait of Georgia where SPD is not known to occur. Prawns in Tank $C$ were fed prawns from Howe Sound that were infected with SPD and prawns in Tank D were not exposed to SPD and served as controls. The arrows indicate the time at which the first dead prawn with SPD was detected in each tank

\section{Laboratory experiments}

During the $123 \mathrm{~d}$ observation period in the first set of laboratory experiments, there was a combined mortality of $95 \%$ among prawns from an affected area in Howe Sound (Tanks $A$ and $B$ ) and a $79 \%$ mortality among prawns which cannibalized SPD infected prawns (Tank C). Of the control prawns (Tank D), 12\% died, but none were infected with SPD (Fig. 5). Of the

Table 2. Results of histological examinations that validate the use of visual appearance of Pandalus platyceros in conjunction with the histological examination of all prawns in Category 2 to determine the prevalence of a rickettsia-like microorganism that causes stained prawn disease (SPD) during field surveys but not during laboratory experiments. Results only include prawns from areas where SPD is known to occur and from experimental tanks where the infection was present

\begin{tabular}{lllll}
\hline \multicolumn{1}{c}{ Category: } & 1 & 2 & 3 & 4 \\
\hline $\begin{array}{l}\text { Visual } \\
\text { appearance: }\end{array}$ & $\begin{array}{l}\text { Normal-looking' } \\
\text { Normal cuticula } \\
\text { colour. No dark } \\
\text { stippling on }\end{array}$ & $\begin{array}{l}\text { Normal cuticula } \\
\text { colour. Faint or } \\
\text { questionable } \\
\text { stippling on } \\
\text { hepatopancreas }\end{array}$ & $\begin{array}{l}\text { Normal cuticula } \\
\text { colour. Dark } \\
\text { stippling on } \\
\text { hepatopancreas }\end{array}$ & $\begin{array}{l}\text { Discolouration } \\
\text { below cuticula. } \\
\text { Dark stippling on } \\
\text { hepatopancreas }\end{array}$ \\
Prawns from & $\mathrm{n}=122$ & $\mathrm{n}=96$ & $\mathrm{n}=35$ \\
field surveys: & $\mathrm{SPD}$ agent $=0 \%$ & $\mathrm{SPD}$ agent $=29 \%$ & $\mathrm{SPD}$ agent $=97 \%$ & $\mathrm{SPD}$ agent $=100 \%$ \\
$\begin{array}{l}\text { Prawns from } \\
\text { laboratory experiments: }\end{array}$ & $\mathrm{n}=179$ & $\mathrm{n}=25$ & $\mathrm{n}=60$ & $\mathrm{n}=0$ \\
\hline
\end{tabular}


89 prawns from Howe Sound (Tanks A and B) that died and were examined, $45 \%$ were found infected with SPD and these infected prawns died throughout the observation period (the other 20 prawns that died were too decomposed or cannibalized to be examined). Stained prawn disease was not observed in the 6 prawns from Tanks A and $B$ that survived to the end of the experiment. The occurrence of SPD in $47 \%$ of the prawns exposed to infected prawns in the laboratory (Tank C) indicates that SPD can be directly transmitted between prawns and this transmission may be facilitated by cannibalism. In Tank C, SPD was first detected in a prawn that was found dead on Day 73. The other infected prawns died at regular intervals throughout the remainder of the incubation period.

In the second set of laboratory experiments, all 18 prawns with visible evidence of SPD at the beginning of the experiment died during the first week of observation (Tank A; Fig. 6). On Day 38, the first SPD infected prawn was found dead in Tank $B$ which had been stocked with prawns from an area where SPD is not known to occur but supplied with screened (to eliminate matter larger than $1 \mathrm{~mm}$ in diameter) outflow water from Tank A. Unfortunately, a second disease that caused severe damage to the gills occurred in Tanks A and B. Extremely high mortalities during Weeks 5 and 6 resulted in the early termination of the prawns remaining in these 2 tanks on Day 42 (Fig. 6). The cause of this second disease was not determined. However, $33 \%$ of the prawns in Tank A and $20 \%$ of the prawns in Tank $B$ were infected with SPD. Prawns in Tanks C and D were not affected by the second unknown disease. Thus, the incubation period in these 2 tanks was extended to Day 96. During the $96 \mathrm{~d}$ period, survival of prawns in Tank $C$, which were fed frozen infected prawns, was good (73\%; Fig. 6). However, $44 \%$ of these prawns were infected with SPD, which indicates that the pathogen can remain infectious for at least $10 \mathrm{~d}$ of storage in a domestic type freezer (about $-10^{\circ} \mathrm{C}$ ). In this tank, the first infected prawn was found dead on Day 55. As in the first set of experiments, mortalities among the control prawns (in Tank D) were low $(9 \%)$ and none were infected with SPD.

In all laboratory experiments, none of the prawns developed the dark discolouration of the cuticula that is characteristic of SPD. However, $58 \%$ of the infected prawns had dark stippling on the hepatopancreas, which is also a trait of SPD. Of the infected prawns,
$17 \%$ had questionable signs of SPD and $25 \%$ appeared normal. The occurrence of SPD in experimental prawns with no visible evidence of the disease indicates that visual examination is not reliable for detecting all infected prawns during laboratory experiments (Table 2).

\section{DISCUSSION}

Although the specific identification of the causative agent of SPD has not been resolved, its morphology and location within cytoplasmic vacuoles in the host cell suggests affiliation with the Order Rickettsiales and Family Rickettsiaceae. Of the 3 tribes included in this family, all species in 2 of the tribes (Tribe I Rickettsieae and Tribe II Ehrlichieae) have vertebrate hosts. However, species in Tribe III Wolbachieae are characterized as being confined to arthropods as pathogens or symbionts and are not pathogenic for vertebrates (Weiss \& Moulder 1984). Also, Rickettsiella grylli from an isopod and an amphipod, the only named species from crustaceans, and an unnamed 


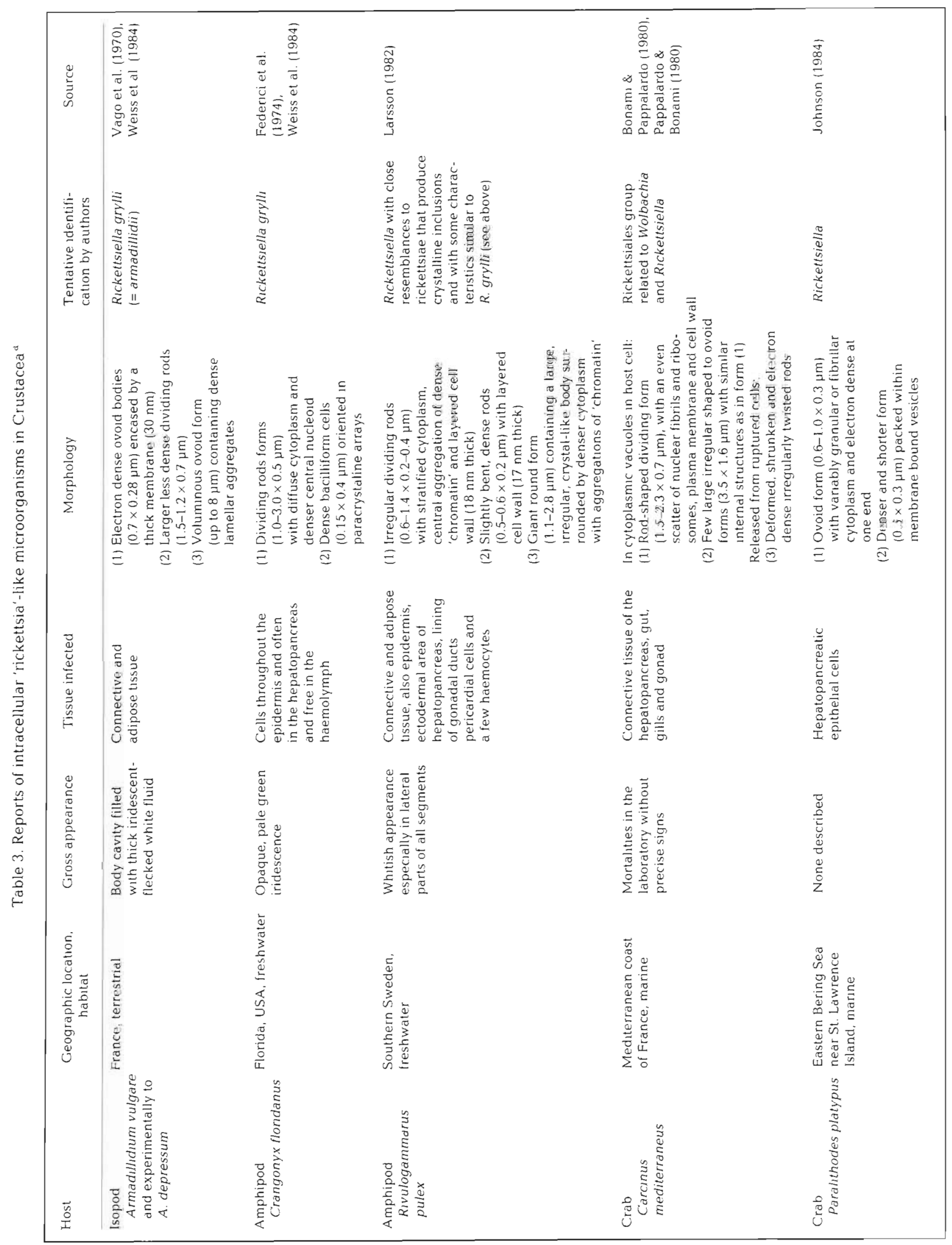




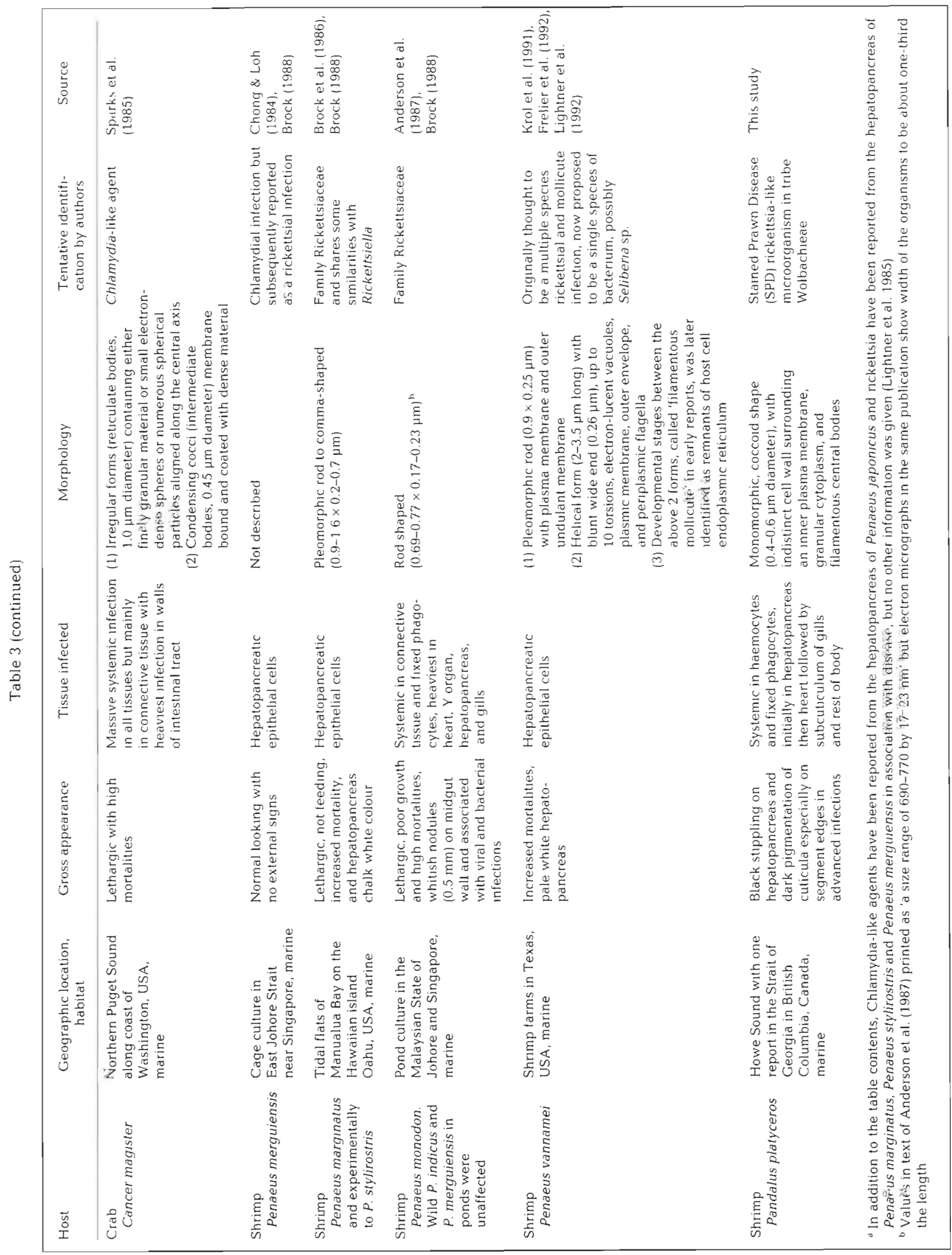


rickettsia-like organism from a crab has been included in this tribe (Weiss et al. 1984). Thus, the SPD organism probably is a member of the tribe Wolbachieae. Brock (1992) noted that diagnosis of RLM from shrimp and prawns relies on histopathology because these infectious agents have not been cultured in vitro on artificial media or in cell culture systems, and because molecular methods have not been developed for their identification. Accordingly, identification of crustacean pathogens in this group has been based on the target cells, related pathology and ultrastructural morphology.

To date 10 different RLM have been reported from 14 crustaceans, including 2 that were experimentally infected by inoculation of material from naturally infected species (Table 3 ). In addition to occurring in a new host, the SPD organism can be differentiated from other RLM by 3 distinctive biological features: morphology, the type of tissue infected, and the gross appearance of the disease. Unlike the monomorphic coccoid shape of the SPD organism, other RLM from Crustacea are pleomorphic and/or include rod or ovoid forms (Table 3). The only RLM that was somewhat coccoid in morphology was described from the Dungeness crab Cancer magister but in this case several different developmental stages were found including forms that were thought to be homologous to the 'reticulate bodies' and 'elementary bodies' of the Chlamydia which are currently not included within the order Rickettsiales (Sparks et al. 1985). These developmental stages have not been observed in the SPD organism.

The second feature that differentiates the SPD organism from all other RLM of Crustacea is the type of host cell that is infected. Unlike the SPD organism which is found exclusively in fixed phagocytes and haemocytes, other RLM parasitize either hepatopancreatic epithelial cells or connective tissue cells (Table 3). Often RLM that infect comnective tissue cells have been reported from other types of cells including fixed phagocytes (Brock 1988). Nevertheless, the SPD organism can be differentiated from these RLM because it has not been observed in connective tissue cells which is apparently a. common host cell of RLM that are not confined to the hepatopancreatic epithelial cells.

The third feature that separates the SPD organism from the other RLM of Crustacea is the gross appearance of heavily infected prawns. Apart from behavioral changes and mortalities, the clinical signs produced by the other RLM were reported as being whitish lesions on organs, or an iridescence, or were not visible (Table 3). However, the SPD organisms caused prawns with advanced infections to appear darkened. Also, infected prawns had black stippling on the hepatopancreas that was apparent before the external dark discolouration developed This subcuticular discolouration may signify long term infections. Its absence in prawns infected in the laboratory may indicate that more than $123 \mathrm{~d}$ after exposure is required for infected prawns to develop the subcuticular discolouration typical of SPD. The dark discolouration of SPD was caused by a melanotic encapsulation of the etiological agent. Haemocyte infiltration, aggregation and encapsulation in responses to RLM have also been reported by Johnson (1984) and Anderson et al. (1987) in the blue king crab Paralithodes platypus, and tiger prawn Pendeus monodon, respectively. However, only Anderson et al. (1987) noted that melanin was involved with the haemocytic response, but visible signs of melanism were not mentioned.

Rickettsia-like microorganisms are not usually considered as serious pathogens of cultured penaeid shrimp (Fulks \& Main 1992). Although RLM wass thought to be primarily responsible for the high mortalities among cultured Penaeus monodon in Malaysia, it occurred in conjunction with a reo-like virus and bacterial infection to produce the disease syndrome (Anderson et al. 1987). The high mortalities associated with SPD infection during the laboratory transmission study reported here were not usually associated with detectable infections of other microbes. Thus, SPD has the potential of being detrimental to shrimp culture if the industry should attempt to culture P. platyceros.

The closure of some areas of Howe Sound to prawn fishing provided an opportunity to study the effects of SPD on natural mortality rates in prawn populations, without the mortality rates being confounded by fishing mortality. The low survival rates calculated for prawns at the Woolridge Island site relative to the other closed areas is a good indication that additional factors were affecting the survival of prawns in the area. Based on the high incidence of SPD in the prawns and the pathological nature of the infection, the low survival rates could easily be ascribed to this disease outbreak. An increase in the natural mortality rate to this extent could virtually eliminate the chances of having a sustainable fishery on prawn populations infected with SPD.

In estimating the potential yield from a fishery, it is common to use the formula of Gulland (1988): $Y=$ $a M B$, where $Y=$ yield, usually $a=0.5, M=$ natural mortality rate, and $B=$ biomass. In this formula, the fishing mortality rate $F=0,5 \mathrm{M}$. From the calculated $M=0.56$ for the closed area of Howe Sound, a sustainable yield from a prawn fishery in that area might have an expected fishing mortality rate of $F=0.28$. The total mortality rate $(Z=F+M)$ on this population would then be 0.84 which is much lower than the calculated $M=1.905$ for the Woolridge Island site where prawns had the highest prevalence of SPD.

The laboratory experiments indicated that SPD was capable of direct horizontal transmission and the infec- 
tive stage could successfully pass through the water between prawns. This free-living stage may have been naked or possibly it was associated with prawn tissue particles less than $1 \mathrm{~mm}$ in diameter. The agent of SPD was first detected in dead prawns between 38 and $72 d$ after exposure in the various experiments. Thus, the prepatent period of the infection is probably about 1 mo. However, substantial mortalities attributable to the disease occurred between 2 and 4 mo after exposure. The resistance of the SPD organism to freezing (in a fashion comparable to that used in the marketing of prawns) suggests that this disease could be easily spread by the activities of the fishing industry.

Unlike the results of Larsson (1982), who found Macchiavello's stain unreliable in staining RLM in the amphipod Rivulogammarus pulex, Macchiavello's stain was found to be the best stain used in the current study. This stain may prove to be a useful diagnostic tool for the detection of the SPD organism.

The interaction between SPD in prawns and industrial contaminants (i.e. dioxin and furan compounds) in the environment was not investigated in this study. It has been hypothesized that environmental contaminants may increase the susceptibility of animals to disease. However, SPD was associated with prawns from areas not known to be affected by environmental contaminants (i.e. Sabine Channel where an infected prawn was found and Snake Island to Neck Point where prawns were obtained and successfully infected in laboratory experiments). Also, prawns from other industrial contaminated areas in Howe Sound were not infected with SPD (i.e. Minaty Bay, Ellesmere Creek, and Furry Creek, Locations 1, 2, and 3, respectively, in Fig 1)

Acknowledgements. We thank Steve Head and Wayne Harling and the captain and crew of the fisheries research vessel 'Caligus' for their technical assistance during the survey component of the work.

\section{LITERATURE CITED}

Anderson IG, Shariff M, Nash G, Nash M (1987) Mortalities of juvenile shrimp, Penaeus monodon, associated with Penaeus monodon baculovirus, cytoplasmic reo-like virus, and rickettsial and bacterial infections, from Malaysian brackishwater ponds. Asian Fish Sci 1:47-64

Bonami JR, Pappalardo R (1980) Rickettsial infection in marine crustacea. Experientia 36:180-181

Boutillier JA (1988) Standardization of effort in the prawn fishery as it relates to biological sampling and escapement management. PSARC Working Paper No. 188-5, Pacific Stock Assessment Review Committee, Nanaimo

Boutillier JA (1993) 1993 review of experimental prawn fishing in Howe Sound. PSARC Working Paper No. 193-4, acific Stock Assessment Review Committee, Nanaimo

Brock JA (1988) Rickettsial infection of penaeid shrimp. In: Sindermann CJ, Lightner DV (eds) Disease diagnosis and control in North American marine aquaculture. Elsevier, New York, p 38-41

Brock JA (1992) Current diagnostic methods for agents and diseases of farmed marine shnmp. In: Fulks $W$, Main KL (eds) Diseases of cultured penaeid shrimp in Asia and the United States. The Oceanic Instıtute, Honolulu, p 209-231

Brock JA, Nakagaw LK, Hayashı T, Teruya S. Van Campen H (1986) Hepatopancreatic rickettsial infection of the penaeid shrimp. Penaeus marginatus (Randall), from Hawail. J Fish Dis 9:73-77

Chong Y (: Loh H (1984) Hepatopancreas chlamydial and parvoviral infections of farmed marine prawns in Singapore. Sing Vet J 9:51-56

Clark G (1981) Staining procedures, 4 th edn. Williams and Wilkıns, Baltimore

Federici BA, Hazard El, Anthony DW (1974) Rickettsia-like organism causing disease in a crangonid amphipod from Florida. Appl Microbiol 28:885-886

Frelier PF, Sis RF, Bell TA, Lewis DH (1992) Microscope and ultrastructural studies of necrotizing hepatopancreatitis in Pacific white shrimp (Penaeus vannamei) cultured in Texas. Vet Pathol 29:269-277

Fulks W, Main KL (1992) Diseases of cultured penaeid shrimp in Asia and the United States. The Oceanic Institute, Honolulu

Gulland JA (1983) Fish stock assessment: a manual of basic methods. FAO/John Wiley \& Sons, Chichester

Gulland JA (1988) Fish population dynamics: the implications for management. John Wiley \& Sons, Chıchester

Johnson PT (1984) A rickettsı of the blue king crab, Paralithodes platypus. J Invert Pathol 44:112-113

Krol RM, Hawkins WE, Overstreet RM (1991) Rickettslal and mollicute infections in hepatopancreatic cells of cultured Pacafic white shrimp (Penaeus vannamel). J Invert Pathol $57: 362-370$

Larsson R (1982) A rickettsial pathogen of the amphipod Rivulogammarus pulex. J Invert Pathol 40:28-35

Lille RD (1965) Histopathologic technic and practical histochemistry. McGraw Hill, New York

Lightner DV, Redman R (1977) Histochemical demonstration of melanin in cellular inflammatory processes of penaeid shrimp. J Invert Pathol 30:298-302

Lightner DV, Redman RM, Bonami JR (1992) Morphological evidence for a single bacterial etıology in Texas necrotizing hepatopancreatitis in Penaeus vannamel (Crustacea: Decapoda). Dis aquat Org 13:235-239

Lightner DV, Redman RM, Williams RR, Mohney LL, Clerx JPM, Bell TA, Brock JA (1985) Recent advances in penaeid virus disease investigations. J World Maricul Soc $16: 267-274$

Pappalardo R, Bonami JR (1980) Etude histopathologique et ultrastructurale d'une maladie rickettsienne chez le crabe Carcinus mediterraneus Czerniavski (Crustacé Décapode). Rev Trav Inst Pêches marit 44:277-283

Ricker WE (1975) Computation and interpretation of biological statistics of fish populations. Bull Fish Res Bd Can 191:1-382

Shaw BL, Battle HI (1957) The gross and microscopic anatomy of the digestive tract of the oyster Crassostrea virginica (Gmelin). Can J Zool 35:325-347

Sparks AK, Morado JF. Hawkes JW (1985) A systemic microbial disease in the Dungeness crab, Cancer magister, caused by a Chlamydia-like organism. J Invert Pathol 45: $204-217$

Vago C, Meynadier G, Juchault P, Legrand JJ, Amargier A, Duthoit JL (1970) Une maladie rickettsienne chez les crustacés isopodes. Cr Acad Sci, Paris D 271:2061-2063 
Weiss E, Dasch GA, Chang KP (1984) Tribe III Wolbachieae Philp 1956. In: Krieg NR (ed) Bergey's manual of systematic bacteriology. Williams \& Wilkins, Baltimore, p $711-717$

Responsible Subject Editor: J. E. Stewart, Dartmouth, Nova Scotia, Canada
Weiss E, Moulder JW (1984) Order I. Rickettsiales Gieszczkiewicz 1939. In: Krieg NR (ed) Bergey's manual of systematic bacteriology. Williams and Wilkins, Baltimore, p $687-688$

Manuscript first received: March 20,1995

Revised version accepted: July 20,1995 